\title{
The development of social presence in online Arabic learning communities
}

\author{
Andrea Hall \\ Sultan Qaboos University \\ Jan Herrington \\ Murdoch University
}

\begin{abstract}
An effective online learning community requires the development of social presence, as this helps learners to project themselves online and feel a sense of community. A literature review found that cultural preferences are important in developing relationships online, which may explain why some learners in international contexts may not participate in the learning community, with an unsuccessful online experience as a result. The effect of culture in the development of a learning community was investigated using a design-based research approach, in two fully online courses for faculty at a university in the Sultanate of Oman. It was found that the participants, all from an Arabic cultural background, preferred to develop responsible relationships before they went online, and preferred to use tools such as synchronous chat that gave increased immediacy to the learning context.
\end{abstract}

\section{Introduction}

Blogs, wikis, forums, social bookmarks and other social and collaborative tools have pushed the social nature of learning to the forefront. Development of an online community is an important aspect of social learning, as the community provides the place where learners can develop trust in others, share their new knowledge, and learn from and with each other. However, there is also research that suggests that cultural values affect the way people learn, and may determine success or failure in learning (Gunawardena, Nolla, Wilson \& Lopez-Islas, 2001; Holmes, 2004; Tu, 2001; Yildiz \& Bichelmeyer, 2003). If cultural preferences do affect how learners become part of, and interact in an online community, then these factors must be considered in the way a course is designed, to enable all students to have equal opportunity for successful learning. Most cultural values are subconscious (Zaharna, 1995), and therefore cultural differences between teachers and students may not be noticed, or the other's perspectives may be seen as unacceptable. This means that if cultural values have a significant role in learning, they need to be identified and accounted for in the design of courses.

The key factor in developing an effective online community is social presence (Polhemus, Shih, Swan \& Richardson, 2000; Rourke, Anderson, Garrison \& Archer, 2001). The term social presence describes the ability to comfortably and effectively communicate through a technical medium. The Social Presence Theory was first proposed by Short, Williams and Christie (1976) and defined as "the degree of salience of the other person in the interaction and the consequent salience of the interpersonal 
relationships" (p. 64). Rourke et al. (2001) redefined the construct for an online environment as "the ability to project socially and affectively into a community of inquirers" (p. 1). Short et al. (1976) explain that social presence is a characteristic of the medium, and also subjective, as people's perceptions vary as to the amount of presence they need. If social presence is low, then people tend to see the medium as cold and impersonal; when social presence is high the medium is perceived as warm, inviting and responsive.

There are two factors that are important in developing social presence: immediacy and intimacy (Swan, 2002b). As illustrated in Figure 1, immediacy behaviours provide the sense of being physically close, whereas intimacy behaviours are verbal behaviours of self disclosure. Learners may perceive different levels of intimacy and immediacy, but there must be sufficient in both to create the warmth and feeling of belonging that is characteristic of a learning community, where learners willingly participate and contribute. For example, Columns $\mathrm{a}$ and $\mathrm{b}$ in Figure 1 both represent learners who have achieved sufficient levels of social presence, whereas the learner represented in Column c has not, as the low level of immediacy is not compensated by increased levels of intimacy.

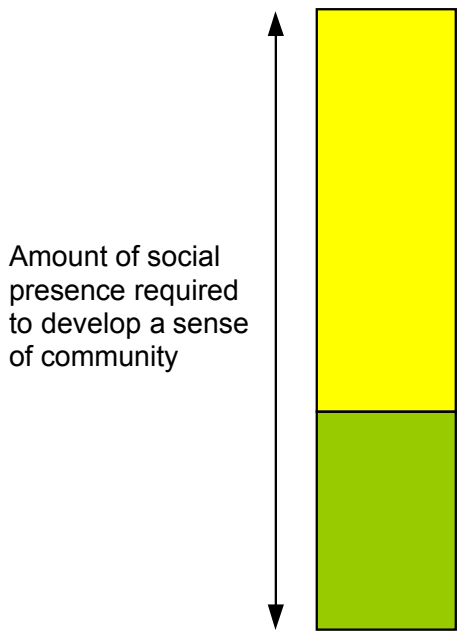

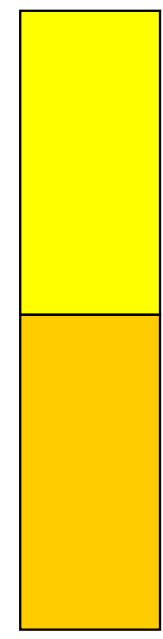

b

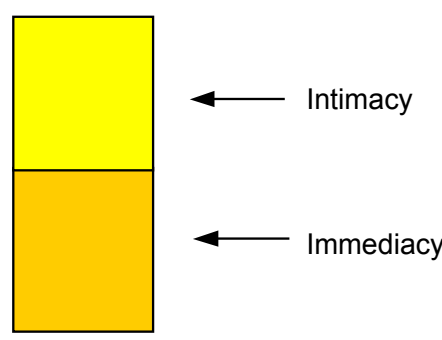

Figure 1: Intimacy and immediacy in social presence, adapted from Swan (2002b, p. 5)

Different online tools support different levels of immediacy, as perceived by the learners, for example, some learners perceive emails and synchronous chats to have more immediacy than asynchronous forums ( Tu, 2002), It is clear then that an investigation into the factors that support the development of a learning community should focus strongly on learners' preferences for developing a sense of social presence. This research investigated how learners from an Arabic cultural context prefer to develop social presence.

\section{Social presence and the development of online community}

A learning community is "a sense that members have a belonging, members matter to one another and to the group and a shared faith that member's needs will be met 
through their commitment to be together' (McMillan \& Chavis, 1986 p. 9). McMillan and Chavis describe four elements found in learning communities, comprising: a feeling of belonging, the ability to influence the group, fulfillment of needs through shared values and goals, and a shared connection with others in the group. These elements need to be present within the technological environment of online courses if a sense of community is to be developed. Research by Fontainha and Gannon-Leary (2008) identified eight critical success factors including the ability to build trust online, developing a sense of belonging with consideration given to culture, and inclusive communication skills. Many of the factors they identify relate to how participants communicate and bond together online, as is supported by the work of Rovai (2002). He found several key issues including the need to overcome the psychological and communications space, work in groups to build connections, maintaining group relationships, and ensuring groups are a suitable size to encourage good connections between the learners. These descriptions highlight the necessity for participants to be able to develop strong committed relationships with one another, so that there is trust, identity and the ability to share personally with others. The technology environment can be a barrier for participants in the ability to build these types of relationships, and the ability to overcome this barrier is identified as social presence.

As social presence is a key factor in the development of a successful learning community, an analysis of such presence helps to explain how learners from different contexts, such as those from the Arab world, can develop a successful learning community, as is the focus of this study. The literature will be examined to identify factors that promote social presence and the significance of learners' cultural values in online communication. Arabic cultural values will also be discussed to highlight the need to investigate how to promote social presence for effective learning communities in the Arab world.

\section{Research on online learners}

A literature review and analysis of research was conducted to investigate how social presence can be promoted. Some studies have suggested that classroom social networks have a significant impact on the development of social presence (Wegerif, 1998). Sufficient interaction is necessary to promote social presence, otherwise learners inevitably find the environment unsupportive and uninviting. However, it is not only the amount of interaction that is important, it is the type of interaction. Self disclosure and the use of affective language are necessary, as they are indicators of the intimacy and immediacy needed in technological environments. Research also shows that social presence should be nurtured throughout the course to maintain the sense of community (Swan, 2002a), and to create trust and a social identity for working collaboratively in online courses (Rogers \& Lea, 2005; Shen, Khalifa \& Yu, 2006).

Teachers also have a role in the development of social presence, through teacher presence and immediacy. Some studies have found that teacher presence, through the design, facilitation and administration of learning, is an important factor to reinforce social presence (Rourke et al., 2001). Ke (2010) found that teaching presence should be developed first, as a catalyst to enable the development of the community. This is supported by the work of Rogers and Lea (2005) who found that social presence was developed as participants worked collaboratively on courses tasks. Teacher immediacy is also important. Immediacy behaviours such as personal emails, feedback or responses in forums increase the sense of presence because they help decrease the 
psychological distance in the online environment (Bozkaya \& Aydin, 2008; Liu, Gomez \& Yen, 2009; Richardson \& Swan, 2003).

Thus, the considerable research in this area has found that the social presence required for the development of community may be promoted by a variety of factors. These include teacher immediacy and collaborative tasks, as well as the way the learners respond; including the way they use affective language and self disclosure to develop an online social identity. However, it is also important to identify the role of culture in the development of social presence.

\section{Research involving learners in other cultural contexts}

A literature review of research with learners from different cultures found that students' communication patterns were culturally dependent. LeBaron, Pulkkinen and Scollin (2000) found that Finnish students in their study communicated less frequently online than did American students. The Chinese graduate students in online courses in Tu's study (2001) also initiated and participated in fewer discussions compared to the Americans in the course. Without the active encouragement of the facilitator, their participation would have been minimal and they would have been "left out of the online community" (p. 52). Perceptions of what constitutes a positive learning community were generally different for the Chinese people in Tu's (2001) study. Tu found that Chinese students interpreted minimal concern in their well-being as "a warm and friendly" atmosphere. They tended not to become actively involved in discussions but would be content to simply observe other students' interactions and contributions. Both LeBaron et al.'s and Tu's study have contributed to understanding of cultural learning characteristics, but questions on social presence remain unanswered, particularly about the nature and extent of online interaction required for the development of social presence, and the role of the facilitator in creating a democratic and inclusive learning environment.

The issue of 'saving face' (i.e. maintaining prestige and honour in social interactions) was also found to be an important construct in the consideration of social presence. Tu (2001) noted the caution required to save face in the way learners in his study composed their discussion contributions. Studies on online learning by $\mathrm{Ku}$ and Lohr (2003) and by Morse (2003) with students from several different cultures, showed much difference in their need for community online, in their level of interest to learn more about others in their courses, and whether or not they wanted to participate in face to face meetings. In another study, Mexican and American graduate students in an online course were found to have significant differences in the nature and frequency of their responses to the tutor, and in the amount of support they gave to each other in the group (Gunawardena et al., 2001). It could also be argued that cultural values may affect a learner's responses to the tutor's immediacy behaviours. This may be the reason for one student being offended by a tutor's comments on an assignment in a multicultural online business course: "Assessment feedback was too direct, a little offensive"; or another student's indifference to a tutor's attempt to create casual, offtask conversation: "I really don't care that the tutor is a world-class surfer" (Dunn \& Marinetti, 2005 p. 3). A Chinese postgraduate student studying in an online course in America commented:

I received an e-mail from the instructor. The text was all in red. I almost passed out. I guessed I might have done or said something wrong or offensive to the teacher, otherwise, the teacher wouldn't written to me this way. (Tu, 2001, p. 52) 
$\mathrm{Tu}$ (2001) commented that the tutor had used this colour for emphasis only, unaware that in the Chinese culture, red is used for warning and correction, and the response of the tutor had promoted anxiety and stress in the student instead of the encouragement and guidance intended. The efforts of the tutors in these examples were either misunderstood or were not appropriate, indicating that an understanding of the learners' cultural background is important in developing social presence and a sense of community.

\section{The need for identifying Arabic cultural preferences that affect social presence}

Most Omanis are Arabs and share cultural values with other Arab societies in the Middle East. Some Omanis are non-Arab, some have grown up in the West, and some are those who historically have settled in Oman or expatriates who have recently gained citizenship. For the purposes of this research, this paper describes the values of those in Oman who culturally identify with the Arabic society.

The Arab society is collectivist and has oral cultural values (Hofstede, 2003; Ong, 1982; Zaharna, 1995; Pollack, 1998). Collectivist cultures emphasise group goals over individual ones, and relationships have a high priority. Close relationships result in commitment and responsibility to others more than to one's own individual needs or opinions, and thus the group provides support, goals and expectations, and expects loyalty (Shkodriani \& Gibbons, 1995; Wu \& Rubin, 2000). People from a collectivist society such as this are motivated by extrinsic, not intrinsic factors. For example, in an individualistic society, self discipline is valued, but in a collectivist society, extrinsic factors such as rules and rewards are more likely to provide motivation. Oral and collectivist cultural values are evident in an Omani society today, in that there is strong loyalty to the wider family, respect for the older people in the community, and motivation through family expectations.

As an oral culture, Arabs value their language as a spoken language in appreciation of its pleasure to the ear, and in the value placed on memorisation and recitation of the Qur'an. Ong (1982) proposed that the way a language is used affects the way people think, because this would determine how knowledge, skills and traditions are transmitted within the society. These values are evident in the society with preferences for communication characteristics that resemble an oral culture, such as rhetoric, exaggeration and a preference for imagery over accuracy (Zaharna, 1995). Knowledge in an oral culture is not abstract but more human related, as traditionally culture and history were held in stories that were told in exaggerated metaphorical ways to aid learning. Consistent with other oral societies, Arabs tend to use very visual methods of learning. Zaharna (1995) explains that this is because they are more people or event oriented and not time or information oriented, and knowledge is less abstract and seen within its natural context. The Arab culture is also described as a 'high context' culture (Hofstede, 2003; Al-Harthi, 2005), that is, communication is more indirect, as the listeners relate to the speaker and thus implicitly know the context or background of the information. The goal of speaking indirectly is to save face and providing harmony, but can provide conflict when communicating with others who are not from that community or culture.

Research on Gulf Arab university students in the United States (Al-Harthi, 2005) identified several learning challenges during their distance learning courses. Al-Harthi aligned these to previously identified national cultural characteristics (Hofstede, 2003). She found that the online environment enabled the students to feel less embarrassed 
about sharing when compared to the classroom, which she related to a cultural value of shame. Her participants also explained they felt the decreased structure of learning online made them feel lazy, which may have related to the cultural value of requiring more structure and extrinsic motivators. Her survey participants also commented on the necessity to avoid conflict, for example, in relation to clarifying course grades with their teachers. Al-Harthi commented that this may have related to either embarrassment or saving face issues, but other non-cultural possibilities were also proposed.

It can be seen that the Arab society has different values from the West, and the work of Al-Harthi indicates that their cultural values can impact their online learning experience. This means it can be assumed that factors in the development of a learning community will also be culturally sensitive, and that courses need to be designed with this in mind. This study sought to investigate to what extent Arabic cultural preferences can be met in the design of the learning, with a particular emphasis on social presence and ability to learn in an online community.

\section{The research approach and method}

The development of a learning community is important in online courses that seek to provide a collaborative networked approach to learning. Research has indicated that social presence is a culturally sensitive concept, and learning may be compromised if learners' cultural preferences are not considered in the design of the course. As little is available on how learners from an Arabic cultural background prefer to learn, or learn in a community, the research was necessary to help the development of an effective learning community. The research was guided by two key questions:

1. How do learners from an Arabic cultural context prefer to develop social presence?

2. In what ways can online courses be designed to facilitate the development of social presence within a learning community?

The research was conducted in the Sultanate of Oman in two three-month courses. A design-based research approach was selected for the study (Collins, Joseph \& Bielaczyc, 2004; The Design-Based Research Collective, 2003). It has a cyclic approach, in that empirical research findings can be applied to the theoretical design and then to the practical design, resulting in continuous modifications of both theory and practice, as is shown in Figure 2.

\section{Design-Based Research}

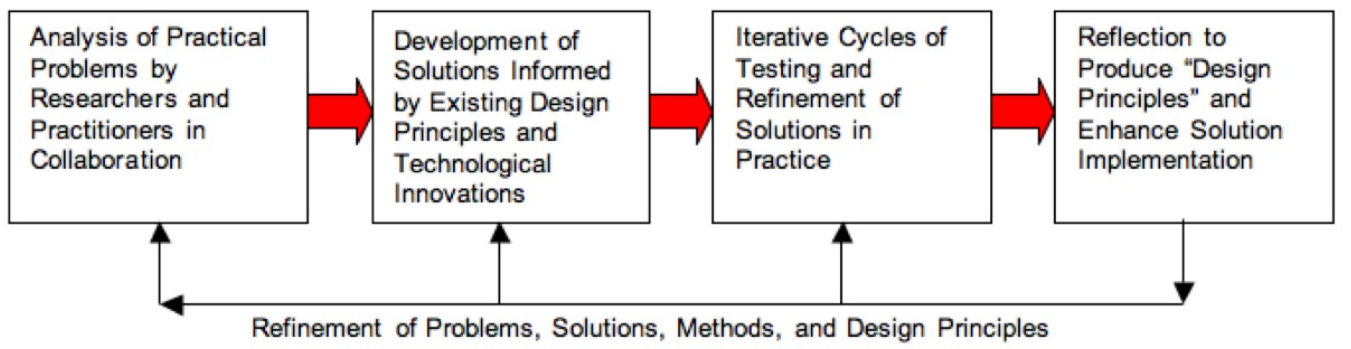

Figure 2: Design-based research (Reeves, 2006, p. 59) 
Within this approach, a case study strategy was used for data collection and analysis. Case studies are used to respond to the 'how' and 'why' questions and the data can be used to modify and improve the research context (Soy, 1997; Yin, 2003). This enables a continuing cycle of change and analysis to identify key issues in the most effective or preferred design solutions. Yin (2003), also comments that this strategy is used when a study focuses on a "contemporary phenomenon within its real-life context" (p. 13).

\section{Context}

The research was carried out on two fully online professional development courses for university faculty on how to teach online, using Moodle, which is a secure virtual learning environment. The courses were designed by the researcher who was also the course facilitator and who had several years experience in designing and implementing online courses. A socio-cultural strategy was used, where interactive work was an integral part of the course design and had an authentic project as the focus of the course (cf. Herrington, Reeves \& Oliver, 2010). The courses were in English and were designed to take eight weeks, with five hours study per week, but most participants took about 12 weeks. No release time or incentives were given, and participants worked on the course mainly during the day in their offices.

There were approximately 12 participants on each course from various cultural backgrounds, The research participants were all the participants from an Arabic cultural background who were willing to participate in the research, and were of different ages, gender, years of teaching experience and from different disciplines, as shown in Table 1. Pseudonyms have been used to protect the participants' identities.

Table 1: Research participant data

\begin{tabular}{|l|c|c|c|c|c|c|c|c|c|}
\hline & \multicolumn{3}{|c|}{ Online course 1 } & \multicolumn{7}{c|}{ Online course 2 } \\
\cline { 2 - 11 } & $\begin{array}{c}\text { Case 1 } \\
\text { Amal }\end{array}$ & $\begin{array}{c}\text { Case 2 } \\
\text { Badar }\end{array}$ & $\begin{array}{c}\text { Case 3 } \\
\text { Dawood }\end{array}$ & $\begin{array}{c}\text { Case 4 } \\
\text { Faiza }\end{array}$ & $\begin{array}{c}\text { Case 5 } \\
\text { Issa }\end{array}$ & $\begin{array}{c}\text { Case 6 } \\
\text { Majid }\end{array}$ & $\begin{array}{c}\text { Case 7 } \\
\text { Nasser }\end{array}$ & $\begin{array}{c}\text { Case 8 } \\
\text { Salim }\end{array}$ & $\begin{array}{c}\text { Case 9 } \\
\text { Talib }\end{array}$ \\
\hline Gender & $\mathrm{F}$ & $\mathrm{M}$ & $\mathrm{M}$ & $\mathrm{F}$ & $\mathrm{M}$ & $\mathrm{M}$ & $\mathrm{M}$ & $\mathrm{M}$ & $\mathrm{M}$ \\
\hline Age & 52 & 40 & 35 & 26 & 42 & 50 & 48 & 45 & 37 \\
\hline Years teaching & 25 & 12 & 2 & 1 & 15 & 19 & 15 & 14 & 8 \\
\hline
\end{tabular}

Both Badar and Faiza had previously studied online but only Majid and Salim knew each other before the course started. All participants except for Salim were proficient in English and taught in English.

\section{Procedure}

While course participants worked on the course, the data were collected and analysed. The analysis informed the modification of the course both theoretically and practically. With each cycle of research, the course was refined to increasingly reflect the preferences and learning needs of the learners. The research tools included participant observation (Hancock, 2002; Hoepfl, 1997; Mertens, 1998), interviews, and analyses of learners' online responses.

During the second online course, a social presence analysis tool, developed by Rourke et al. (2001) was also used. This tool measures three categories of communicative responses that contribute to social presence: affective, interactive and cohesive responses. Rourke et al. (2001) developed the tool to measure social presence density, but in this 
research it was used to identify any missing elements in social presence from the research in the first online course.

\section{Results}

\section{The first online course}

Analysis of the first online course found that the three participants showed little sense of belonging to a learning community. Their interaction with the course materials and other participants was very low, as indicated by statistics provided in the Moodle learning management system, and they had all commented in their interviews that they felt they were working alone.

I feel alone and on my own. This is a good for me but for students at a young age, if it is the same feeling it will be bad or maybe isolated. [Interview with Amal]

At the moment I feel am working alone. I need to start doing it [interact] otherwise I'll miss the train,... the course train. [Interview with Badar]

I feel alone so far but in a day or two I feel I will be getting into the community. I know I should read more to get into the family of the course. [Interview with Dawood]

The emails and welcome notes from the facilitator did not appear to contribute greatly to a sense of belonging. Nevertheless, all the research participants suggested that there should be more chats and email messages from the facilitator; and these were added to the course.

If we had a certain hour for all students to be online together - this could be better. It is the touching between emails and the mails from the Moodle itself. I feel you [the facilitator] always are there. [Interview with Amal]

I think if you could contact them to ask how they are keeping would give some motivation to contribute and interact more. I think have a time agreed by all to meet on is very good idea, for structure that will enhance the communication. [Interview with Badar]

Two chat sessions per week were initiated by the facilitator, based on the times participants would be available, to help them discuss how they would complete the stages in their projects. Additional weekly email messages were also sent by the teacher to support appropriate activities in Weeks 2-6 of the course. However, analysis of Moodle interaction statistics during the following three weeks revealed that the extra chats and emails from the facilitator appeared not to facilitate increased interaction and that a sense of community was not evident:

I start to read the postings and then I wander around the course. And therefore, there's a kind of disorientation. Learning alone. [Interview with Badar]

To be honest, I feel the course is a bit dry. I told you that in the beginning because there is less contact between the participants. Everyone is like on a different island. [Interview with Dawood]

Participants did suggest that this lack of interaction and sense of community related to commitment: 
I am actually motivated and like the course very much. I want to do it but yet it comes in number five on my list. Obligation might accompany dedication where this has to reach number one priority. [Interview with Dawood]

I think once I make an arrangement with someone to meet on a specific time [online] that will make me feel obliged to be there and we both need to carry the weight to progress. [Interview with Badar]

All three participants continued to comment on the importance of the face to face, and their desire to be able to share at a more personal level which would make "barriers disappear" (Dawood) and provide the "human factor" (Amal) they felt the course lacked.

Further changes to the course included the redesign of some tasks to enable participants to work more responsibly and inclusively with each other. However, this did not help increase a sense of community, and two of the three participants did not complete the course.

In summary, an analysis of the first course found that although there was a desire to learn and complete the course, only one research participant was able to do so. Interaction was low and learning was compromised for all as they did not complete all course tasks. They all had problems with a lack of the human touch in the course, lack of a sufficient face to face element, and no sense of community. Although more support, a mid-term, face to face meeting, and more opportunities for developing responsibility to others were provided, these did not improve participant engagement in the course. Further investigation was required.

\section{The second online course}

In this course, there were six cases and two research cycles. The first cycle was completed immediately after the first unit of this course, and the second after the course completion. The course started with a face to face orientation unit where participants could meet others and learn in groups to get to know each other. Not everyone stayed for the whole session, and as the location of the laboratory setting was not conducive to face to face socialising, group interaction was not very effective, with some not meeting other group members in this session. Interaction continued to be poor.

In my state of mind, I feel I am working alone. It is probably there [the community] but I didn't look at it, the forums, but I didn't notice them. [Interview with Majid]

I feel I am alone. I try to contact with others but no others are online to chat with for discussion something about the course. Many times I enter the course but I cannot find others online so I close the computer. [Interview with Salim]

As a result of the first cycle of research in this course, more group chats were designed into the course, and participants were encouraged to participate. Participation increased in the chats but not the forums, and participants continued to express a lack of sense of community.

In the chat, it's seldom that you get someone to chat with you ... So it's like working alone. [Interview with Talib] 
As represented in Table 2, participant comments in the forums and chats were analysed for social presence indicators, using affective, cohesive and interactive tools, (Rourke et al., 2001, and as further defined in the Table 2 key).

Table 2: Social presence indicators

\begin{tabular}{|c|c|c|c|c|c|c|c|}
\hline & \multicolumn{3}{|c|}{ Forums } & \multicolumn{3}{|c|}{ Chat } \\
\hline & & Affective & Cohesive & Interactive & Affective & Cohesive & Interactive \\
\hline \multirow[t]{6}{*}{ 1st cycle } & Faiza & 8 & 11 & 11 & 1 & 10 & 28 \\
\hline & Issa & 0 & 0 & 0 & 0 & 3 & 6 \\
\hline & Majid & 0 & 1 & 1 & \multicolumn{3}{|c|}{ No participation } \\
\hline & Nasser & \multicolumn{3}{|c|}{ No participation } & \multicolumn{3}{|c|}{ No participation } \\
\hline & Salim & 0 & 0 & 0 & \multicolumn{3}{|c|}{ No participation } \\
\hline & Talib & \multicolumn{3}{|c|}{ No participation } & \multicolumn{3}{|c|}{ No participation } \\
\hline \multirow[t]{6}{*}{ 2nd cycle } & Faiza & 7 & 11 & 10 & 8 & 13 & 94 \\
\hline & Issa & \multicolumn{3}{|c|}{ No participation } & 0 & 2 & 34 \\
\hline & Majid & \multicolumn{3}{|c|}{ No participation } & 0 & 12 & 38 \\
\hline & Nasser & \multicolumn{3}{|c|}{ No participation } & 0 & 3 & 28 \\
\hline & Salim & \multicolumn{3}{|c|}{ No participation } & 0 & 6 & 20 \\
\hline & Talib & 0 & 0 & 0 & 0 & 0 & 14 \\
\hline
\end{tabular}

Key: Affective response: words showing emotions, feelings or mood, such as using humour and self disclosure.

Cohesive responses: words that build a sense of group commitment such as using "we", "our" or "us".

Interactive responses: Evidence of attending to others responses, by replying directly to their comments.

As can be seen in Table 2, there was a strong preference for chats, compared to forums. In the second part of the course, all participants were involved in the chat, but only two in the forums. Everyone commented on their preference for using chat, because it was less formal and had more immediacy:

Using the chat is much more easy for discussing. You come fresh from the reading and you don't have anything in your mind. You start chatting with each other and you help each other come out with certain ideas or certain thinking or something like that. [Interview with Talib]

I think I find it easier to write in chat than in forum. The forum is a learning process, exchanging ideas... [it] is new so it needs some time. And the other thing the way we are taught in Oman, is just sitting in the class, right, listening to the teacher; at the end of it just get out and go back home. We don't have this kind of discussion. [Interview with Issa]

Chats, it's more lively than forums. You may say something and then receive no response. But in the chat you are sure to get someone to say something. So I felt, you know where we have communication I felt comfortable [Interview with Faiza]

However, apart from Faiza, there was still only a limited participation in the chat activities suggesting that online interaction was not the preferred place to develop a sense of community for most cases.

Comments from the interviews suggest that face to face time at the beginning of the course is the best time to develop a sense of community. During the interviews, 
participants commented on the necessity of feeling a sense of commitment to each other, that this must be present before they would interact.

The thing with this course is that everything is done remotely, that type of relationship is not built. It is most likely built only in the face to face situation. If the first part of the course will be in a class, even not a class, a group meeting. From my group I know only one who I knew from before the course. You know there was no commitment made for the course. [Interview with Talib]

Maybe it will enhance the commitment to the course if you have a direct [face to face] relation with the class [at the beginning]. [Interview with Nasser]

I think if we want, to make people feel more part of the group, before beginning the course, we must, should have taught us as a group in your lab. I think, if you want if you want to make a successful group in the course, make the social group before the beginning. [Interview with Salim]

One participant commented on the importance of face to face in developing responsibility:

Actually I definitely feel guilty toward my group that a part of the web that's definitely lacking not contributing. But since it's online, I probably don't meet them so I don't feel embarrassed. If you get them to know each other at the beginning and get them to have face to face on lab chat and talk, personally, I think they will have more obligation to be online later in the course or throughout the course. [Interview with Majid]

This suggests that face to face orientation is crucial in enabling most learners to get to know each other and feel a sense of responsibility toward each other, and then interaction and a sense of community could develop.

As evident in Table 2, there was virtually no self disclosure in the communication. There was only one participant using affective social presence indicators, and she was the only one who felt a sense of community and responsibility to others from the beginning. She commented that she felt comfortable in developing relationships online and felt a sense of responsibility to her group members. The other five cases expressed 157 social presence indicators in their chats in the final research cycle. Of these, none were affective responses, $15 \%$ were cohesive and $85 \%$ were interactive. These results are compared with data gathered from other research studies (Stacey, 2000; Swan, 2002b; Yildiz, 2009) in Table 3.

Table 3: Comparing social presence indicators in research examples

\begin{tabular}{|l|c|c|c|c|}
\hline \multicolumn{1}{|c|}{ Sample } & Affective & Cohesive & Interactive & Source \\
\hline Post graduate distance course in Australia & $25 \%$ & $31 \%$ & $43 \%$ & (Stacey, 2000) \\
\hline Post graduate education course in USA & $49 \%$ & $17 \%$ & $34 \%$ & (Swan, 2002b) \\
\hline Post graduate language course in USA & $24 \%$ & $17 \%$ & $59 \%$ & (Yildiz, 2009) \\
\hline This course in Oman & $0 \%$ & $15 \%$ & $85 \%$ & \\
\hline
\end{tabular}

Participants in the first three courses shown in Table 3 worked as an online community or group, but participants in this research did not. The figures presented in Table 2 suggest that the lack of affective responses for five out of the six participants in this course is a significantly different result, and indicates the lack of affective responses meant there were no intimacy behaviours that were needed to provide the social 
presence to develop or maintain a learning community. Participants commented on the difficulty in sharing where they did not know others well:

When you know people, you are more open with them. You keep out your private life when you don't know how they will react to it. [Interview with Majid]

We don't feel it's right to discuss some things of your private life with people you don't know. I like sharing some of my private life with someone I have a relationship with. [Interview with Talib]

This was noted in the first online course, which Badar related to the values of his society:

A lot of people didn't really like to humiliate themselves in the way they think they are. I actually appreciate it when people say 'I don't understand this' [or] 'well this doesn't work'. And you are in a society where opinion matters. So a word could make the person higher up and another word could send him down. [Interview with Badar]

This suggests that the orientation must not only help build responsible relationships, it should also help participants know each other sufficiently to overcome barriers for sharing at a personal level.

\section{Discussion}

This research found that the participants from an Arabic cultural background found it difficult to feel part of a learning community in the online course that they were involved in. They strongly preferred to start the course with a face to face component and work in groups. The face to face component would provide them with the opportunity to get to know others in their group well enough to be able to share at a more personal level, that is, to provide the intimacy needed to compensate the lack of immediacy of the online environment (Swan, 2002b). It was also found that responsibility to others was important. This is consistent with the values of collectivist cultures such as the Arabic society where relationships are paramount (Hofstede, 2003; Zaharna, 1995). The face to face component at the start of the course may reflect the preference of the human element of oral societies and its visual learning tools. This is affirmed in students' lack of interaction online, especially in the forums. Participants showed reluctance to share personally with those they did not know well and as a result, the learning community did not develop.

Participants' preference for chats over forums suggests they liked the instant responses, and the feeling that others are online at the same time. However, it may have related also to how knowledge is developed using these two tools. With asynchronous forums, a person's opinion is clearly stated; but in a synchronous chat, opinions can be developed as a group through ongoing discussion. There was a strong reluctance to use the forum, possibly because its asynchronous nature means that what is written is an opinion, and it may stand as 'published' for many days before others comment. A post is an individual's contribution, not the teacher's, and students take a risk in putting their opinions 'out there' to be judged, perhaps with a loss of face (Al Harthi, 2005). One participant expressed surprise at another young Omani in the course giving opinions in front of others in the forum, describing it as very 'modern'. Another respondent, commenting on forum posts noted that 'opinions matter'. On the other hand, a chat happens in real time, and what evolves over a short space of time is a group opinion, even in its evolution. Because it is collaborative, students are not 
setting themselves up as equal with the teacher, and this form of communication is more acceptable in collectivist cultures (Shkodriani \& Gibbons, 1995; Wu \& Rubin, 2000).

Collectivist societies prefer a group opinion over the individual (Wu \& Robbins, 2000), and this may be an alternative reason for the reluctance to use the forums. As these cultural preferences all relate to the initial part of the course in developing relationships, it suggests that more attention needs to be paid to the design of the initial part of the course. It should enable participants to first build relationships so they may feel responsible towards others in the course, to be able to share more personally, and to use the type of communication that builds a learning community through effective social presence.

The findings from this research suggest that in developing a learning community, an online course should start where possible with a face to face component or its electronic equivalent (such as video conferencing, video chats, and visual communication technologies). Course tasks should be addressed mainly to groups and use a group leader who can encourage responsibility amongst the members. Participants should be given the opportunity to get to know group members well enough in the face to face meeting to develop responsibility and commitment to each other, and to enable them to feel comfortable in sharing more personally with each other using additional immediacy tools for communication, as well as those that are available within the course. Regular, group face to face meetings should also be encouraged, to support social presence, and groups should be selected where possible on a geographical basis to encourage group meetings. If courses do not have the opportunity to start in a face to face situation, visual communication tools should be used in a way that best supports learners' visual immediacy learning preferences. As technology advances, such tools are becoming less intrusive and more natural and seamless in their use.

This research identified how learners from an Arabic culture preferred to develop social presence for learning as a community. The research was with adult learners; arguably there may be different preferences with younger learners such as in their ability to form relationships and interact in the online environment. This means that the suggestions for developing learning communities for learners from Arabic contexts may need to be modified for different groups of learners. Further research is necessary to help ensure the learning design accommodates how the participants prefer to develop a learning community.

\section{Conclusion}

The online environment presents a technological barrier that must be overcome before learners may participate as part of a community of learners. Learners must be able to develop a sense of social presence - the ability to project oneself in the online medium - before they can become part of a learning community. However, the development of social presence is culturally imbued, and online courses need to be designed in a way that considers learners' cultural values.

The first aim of the research was to identify how learners from an Arabic cultural context prefer to learn. This research found that learners from an Arabic cultural context prefer to develop relationships within groups and in a face to face 
environment, especially at the beginning of a course. Sufficient time is required for learners to feel responsible and committed to each other in the group, as this will then enable them to share at a more personal level, and therefore help provide the level of intimacy needed for developing an online community. It was also found that elearning tools that enable higher immediacy behaviours, such as chat and email, are preferred.

The second aim of this research was to propose how courses can be designed for learners from this cultural context. The findings suggest that where possible, online courses should start in a face to face situation that enables participant socialisation sufficient to enable responsibility to each other and sharing at a personal level. Participants should also be encouraged to communicate with each other using any immediacy tools available, as well as regular face to face meetings with those in the same geographical location. Where learners cannot meet others from the course, visual communication tools should be sought and used in a way that best supports learners' visual immediacy preferences.

The influence of culture on the development of a learning community is significant, and must be considered in the design of learning if every student is to have an equal opportunity for success.

\section{References}

Al-Harthi, A. S. (2005). Distance higher education experiences of Arab gulf students in the United States: A cultural perspective. The International Review of Research in Open and Distance Learning, 6(3). http: / / www.irrodl.org/index.php/irrodl/article/viewArticle/263/406

Bozkaya, M. \& Aydin, I. E. (2008). The relationship between teacher immediacy behaviors and learners' perceptions of social presence and satisfaction in open and distance education: The case of Anadoulu University Open Education Faculty. The Turkish Online Journal of Educational Technology, 7(3), 64-70. http:/ / www.tojet.net/articles/737.pdf

Collins, A., Joseph, D. \& Bielaczyc, K. (2004). Design research: Theoretical and methodological issues. Journal of the Learning Sciences, 13(1), 15- 42.

Dunn, P. \& Marinetti, A. (2005). Cultural adaptation: Necessity for global elearning. New Economy e-Magazine. [viewed 11 July 2010] http:/ / www.linezine.com/7.2/articles/pdamca.htm

Fontainha, E. \& Gannon-Leary P. M. (2008). Communities of practice and virtual learning communities: Benefits, barriers and success factors. Elearning Papers No. 5. http: / / www.elearningeuropa.info/ files / media/media13563.pdf

Gunawardena, N., Wilson, P. L. \& Lopez-Islas, J. R. (2001). A cross-cultural study of group process and development in online conferences. Distance Education, 22(1), 85-122.

Hancock, B. (2002). Trent focus for research and development in primary healthcare: An introduction to qualitative research. [viewed 20 Jun 2009; not found 21 Dec 2010] http: / / www.trentrdsu.org.uk/cms/uploads/Qualitative\%20Research.pdf

Havelock, E. (1986). The muse learns to write: Reflections on orality and literacy from antiquity to the present. New Haven: YUP.

Herrington, J., Reeves, T. C. \& Oliver, R. (2010). A guide to authentic e-learning. London: Routledge.

Hoepfl, M. (1997). Choosing qualitative research: A primer for technology education researchers. Journal of Technology Education, 9(1), 47-63. 
Hofstede, G. (2003). Geert Hofstede cultural dimensions. [viewed 10 Jun 2010] http:/ / www.geerthofstede.com/

Holmes, P. (2004). Negotiating differences in learning and intercultural communication: Ethnic Chinese students in a New Zealand university. Business Communication Quarterly, 67(3), 294307.

Ke, F. (2010). Examining online teaching, cognitive, and social presence for adult students. Computers \& Education, 55(2), 808-820.

Ku, H.-Y. \& Lohr, L. L. (2003). A case study of Chinese students' attitudes toward their first online learning experience. Educational Technology, Research E Development, 51(3), 95-102.

LeBaron, J., Pulkkinen, J. \& Scollin, P. (2000). Problems of student communication in a crosscultural, international internet course setting. In World Conference on Educational Multimedia, Hypermedia and Telecommunications. (pp. 523-528). Montreal, Canada.

Liu, S. Y., Gomez, J. \& Yen, C.-J. (2009). Community college online course retention and final grade: Predictability of social presence. Journal of Interactive Online Learning, 8(2), 165-182. [verified 21 Dec 2010] http:/ / ncolr.org/jiol/issues/pdf/ 8.2.5.pdf

McMillan, D. W. \& Chavis, D. M. (1986). Sense of community: A definition and theory. Journal of Community Psychology, 14, 6-23.

Mertens, D. M. (1998). Research methods in education and psychology: Integrating diversity with qualitative and quantitative approaches. Thousand Oaks: Sage.

Morse, K. (2003). Does one size fit all? Exploring asynchronous learning in a multicultural environment. Journal of Asynchronous Learning Networks, 7(1), 37-55.

Ong, W. J. (1982). Orality and literacy: The technologizing of the world. London: Routledge.

Polhemus, L., Shih, L.-F., Swan, K. \& Richardson, J. (2000). Building affective learning community: Social presence \& learning engagement. Paper presented at the World Conference on the WWW and Internet.

Pollack, K. M. (1998). Arab culture and Arab military performance: Tracing the transmission mechanism. Ideas, Culture and Political Analysis Workshop. [viewed 14 Oct 2002; not open access] http:/ / www.ciaonet.org/conf/ssr01/ss01af.html

Reeves, T. C. (2006). Design research from a technology perspective. In J. van den Akker, K. Gravemeijer, S. McKenney \& H. Nieveen (Eds.), Educational design research. London: Routledge.

Richardson, J. \& Swan, K. (2003). Examining social presence in online courses in relation to students' perceived learning and satisfaction. Journal of Asynchronous Learning Networks, 7(1), 68-88.

Rogers, P. \& Lea, M. (2005). Social presence in distributed group environments: The role of social identity. Behaviour \& Information Technology, 24(2), 151-158.

Rourke, L., Anderson, T., Garrison, D. R. \& Archer, W. (2001). Assessing social presence in asynchronous text-based computer conferencing. Journal of Distance Education, 14(2). [verified 21 Dec 2010] http: / / auspace.athabascau.ca:8080/dspace/ bitstream/2149/732/1/Assessing\% 20Social\%20Presence\%20In\%20Asynchronous\%20Text-based\%20Computer\%20Conferencing.pdf

Rovai, A. P. (2002). Building a sense of community at a distance. The International Review of Research in Open and Distance Learning, 3(1), 1-12. http: / / www.irrodl.org/index.php/irrodl/article/view/79/152

Shen, K. N., Khalifa, M. \& Yu, A. Y. (2006). Supporting social interaction in virtual communities: Role of social presence. Paper presented at the Twelfth Americas Conference on Information Systems, Acapulco, Mexico. [verified 21 Dec 2010]

http: / / aisel.aisnet.org / cgi/ viewcontent.cgi?article=2075\&context=amcis2006 
Shkodriani, G. M. \& Gibbons, J. L. (1995). Individualism and collectivism among university students in Mexico and the United States. The Journal of Social Psychology, 135(6), 765-780.

Short, J., Williams, E. \& Christie, B. (1976). The social psychology of telecommunications. London: John Wiley.

Soy, S. K. (1997). The case study as a research method. [viewed 11 Jul 2010, verified 21 Dec 2010] http: / / www.ischool.utexas.edu/ ssoy/ usesusers/1391d1b.htm

Stacey, E. (2000). Quality online participation: Establishing social presence. In Evans, T. (Ed), Research in Distance Education 5: Revised papers from the 5th Research in Distance Education Conference. Geelong, December 2000 (pp. 138-153).

Swan, K. (2002a). Building learning communities in online courses: The importance of interaction. Education, Communication E Information, 2(1), 23-49.

Swan, K. (2002b). Immediacy, social presence, and asynchronous discussion. In J. Bourne \& J. C. Moore (Eds.), Elements of quality online education (Vol. 3, pp. 1-21). Needham, MA: Sloan Center.

The Design-Based-Research-Collective (2003). Design-based research: An emerging paradigm for educational inquiry. Educational Researcher, 32(1), 5-8.

Tu, C.-H. (2001). How Chinese perceive social presence: An examination of interaction in online learning environment. Educational Media International, 38(1), 45-61.

$\mathrm{Tu}, \mathrm{C} .-\mathrm{H}$. (2002). The measurement of social presence in an online learning environment. International Journal on E-Learning, 1(2), 34-45.

Wegerif, R. (1998). The social dimension of asynchronous learning networks. Journal of Asynchronous Learning Networks, 2(1).

Wu, S.-Y. \& Rubin, D. L. (2000). Evaluating the impact of collectivism and individualism on argumentative writing by Chinese and North American college students. Research in the Teaching of English, 35(2), 148-179.

Yildiz, S. (2009). Social presence in the web-based classroom: Implications for intercultural communication. Journal of Studies in International Education, 13(1), 46-65.

Yildiz, S. \& Bichelmeyer, B. A. (2003). Exploring electronic forum participation and interaction by EFL speakers in two web-based graduate-level courses. Distance Education, 24(2), 175-193.

Yin, R. K. (2003). Case study research: Design and methods. Thousand Oaks: Sage.

Zaharna, R. S. (1995). Bridging cultural differences: American public relations practices and Arab communication patterns. Public Relations Review, 21(3), 241-255.

\author{
Andrea Hall \\ Department of Learning and Teaching, Sultan Qaboos University \\ Email: andreah@squ.edu.om \\ Professor Jan Herrington \\ School of Education, Murdoch University, Murdoch WA 6150, Australia \\ Email: j.herrington@murdoch.edu.au
}

